items direct debiting can take away the unenviable task of juggling between household items. Household food intake often suffers as a result.

Secondly, the restructuring of the UK grocery market, or, more exactly, the collapse of the number of retailing grocery outlets, which halved between 1974 and 1983, has meant the removal of credit for food for the poor. "Tick" at the local shop is a thing of the past.

Thirdly, the availability of nutritious good quality food is now in some respects more problematic than in the 1930 s because the past 30 years have seen the rise of high value added foods, which tend to have low nutritional value.

Fourthly, in the 1930s food, or its lack, was an issue of the greatest public concern, whereas today the welcome return of interest in food policy has been based on the mistaken assumption that many mass food problems are those of an affluent society. In truth, the problems of food scarcity are still here today for millions of people in Britain at the same time as those problems mistakenly attributed to affluence.

Finally, food overproduction, or overproductive capacity, there may have been in both the imperial 1930s and the European Community 1980s, but the existence of food surpluses bears little relation to the social distribution of food. Then, as now cash mediates between need and access to food.

T M LANG

I.ondon Food Commission.

London N5 IDU

SIR,-I have great esteem for the $B M \mathcal{F}$ as a journa of medical science with a provision for affairs of medicopolitical value. I am disgusted and ashamed to observe Dr J Munro's personal views printed in your pages (16 November, p 1427). I trust that you will not degenerate into a (fascist) political magazine.

VAUGHAN ROBERTS

Alnwick,

Northumberland NE66 2PS

** Our correspondence columns exist to allow comment and discussion about the papers we publish. The fact that we print a letter does no necessarily imply that we agree with the sentiments it expresses. We think unemployment is an important issue and would welcome constructive debate. $-\mathrm{ED}, B M \mathcal{F}$

\section{Proposal for ethical standards in therapeutic} trials

SIR,-Dr Ian Lennox-Smith (2 November, p 1279) and your other correspondents (16 November, p 1422) defend trials in normal healthy volunteers, which the ethical committee of the Service des Maladies Sanguines et Tumorales has condemned $^{1-3}$ on the grounds that any subject submitted to a trial should have something to hope for from the studied treatment and nothing to risk. A normal healthy subject has by definition nothing to hope for and takes the risk of a toxic effect when nobody can affirm that a given drug is not toxic: aspirin ${ }^{4}$ and non-steroidal anti-inflammatory drugs $^{5}$ are examples of drugs which one would initially accept for study in normal subjects and which long term use has shown to be possibly toxic.

As for phase I studies, ' for the same reasons the committee considered it unacceptable to apply doses which are not efficient, as is done in the interpatient escalation models. We have therefore used, even for cytostatic agents, the intrapatient escalation model with the advantage of finding more beneficial results, as all patients finally received an efficient dose-and without incident."

So far as informed consent is concerned, I have only to quote the case of the patient who died from a trial which was not necessary for her, to which she did not consent, and to which her husband was totally opposed.

On randomisation the committee considered our demonstration that in disease free survival and in survival exponential curves there are usually three subgroups with different slopes and that the last is often parallel to the normal life expectancy, which means that the patients represented are cured..$^{89} \mathrm{It}$ is not ethical to submit half of them to the toxicity of a treatment which may induce late severe complications, as shown by Howell et al in a trial of cyclophosphamide, methotrexate, and fluorouracil ${ }^{10}$ which showed no benefit on survival but severe bone marrow lesions. " Thus instead of applying a treatment to all patients, as in conventional randomised controlled trials, we conduct two trials, generally applying two different treatments, one on patients on the first rapid slope segment, another on those on the second moderate slope segment, and none on the cured patients.

The fact that the ethical and medical problems of clinical trials have not yet been solved should encourage the study of new models ${ }^{612}$ and reflections broader than those of pharmacological considerations. The best solution is that all citizens know the methods: for this reason, we are creating an international society of patients who refuse to be randomised for any treatment.

Institut de Cancérologie

Georges Mathé

d'Immunogénètique,

Group Hospitalier Paul-Brousse,

94800 Villejuif, France

1 Durry G, Dion S. Considérations sur l'éthique des études phase I. Biomed Pharmacother 1984;38:423-4

2 Dion S. Considérations sur l'éthique des études phase II. Biomed Pharmacother 1984;38:425.

3 Arpaillange P, Dion S. Considerations sur l'éthique de la randomisation. Biomed Pharmacother 1984;38:426-9.

4 Assouline SR. Prudence avec l'aspirine. Pratique Médical Quotidienne 1985;156:6.

5 Mattison N. Unexpected side effects: the regulatory implications of the Oraflex and Zomax withdrawals in the USA Pharmaceut Med 1984;1:13-6.

6 Mathé $\mathrm{G}$, Triana $\mathrm{K}$. Intrapatient escalation in phase I trial of $\mathrm{L}$ OHP. Clin Pharmacol Res (in press

7 Brahams D. Death of patient participating in trial of ora morphine for relief of postoperative pain. Lancet 1984;i: $1083-4$

8 Eriguchi, Mathé G. Analysis of survival and DFS curves: for understanding the effect of adjuvant therapy of malignan disease. Oncologia 1985;12:146-8

9 Mathé G, Gouveia J, Eriguchi M, Reizenstein P. Passive, adoptive and active immunotherapy: a review of clinical trials in cancer. Med Oncol Tumor Pharmacother (in press)

10 Howell A, George WD, Crowther D. Controlled trial of adjuvant chemotherapy with crclophosphamide, methotrexate and fuorouracil for breast cancer. Lancet 1984;ii: $307-11$

11 Howart JMT, Howell A, Testa NG. Paterson laboratory and medical oncologv annual report. Manchester: Trafford, 1983

12 Mathé G, Eriguchi $M$. A new model for comparative trials based on the multisegment slope of disease-free survival and survival curve. Biomed Pharmacother (in press).

\section{Osteopathic manipulation resulting in damage to the spinal cord}

SIR,-Dr C Davis writes about the British Society of Osteopathy (30 November, p 1540). As there is no such society one does not know what kind of osteopath manipulated his second patient, and, indeed, all three patients may have been treated by unregistered and untrained osteopaths.

Furthermore, he states that the medicolegal implications of doctor to osteopath referrals are self evident. I find it impossible to believe that any general practitioner would have referred any of these particular cases to an osteopath or even to a consultant in osteopathic medicine for they are all cases which are obviously unsuitable for manipulation.

The first reported case should not have been manipulated. Pain, paresis, or Lhermitte's sign in all four limbs is a contraindication to manipulation. In the second case manipulation of the lumbar spine at the age of 70 is quite acceptable, but to treat a cervical spine at that age with any treatment other than gentle traction is not acceptable. With regard to the third case, any patient who looks ill or has lost weight should be investigated before treatment. If these patients had been treated by a consultant in osteopathic medicine, or a member of the Register of Osteopaths, these accidents would have been avoided.

Furthermore, to my knowledge, there are no published reports of any accidents caused by a consultant in osteopathic medicine. Members of my association treat many doctors, including neurosurgeons and orthopaedic surgeons. I find it hard to believe that if osteopathic manipulation has no beneficial results, or is actually harmful, such patients would come to the members of my association for treatment.

JoHN DAVIDSON Chairman

Osteopathic Medical Association.

London $\mathrm{W} 1$

SIR,-Mr C Davis has quite rightly brought to our notice three cases in which osteopathic manipulation is assumed to have resulted in acute spinal cord injury requiring surgery. It is good to know that in two of these cases appropriate skilled surgical intervention was effective in minimising subsequent morbidity, and that only in the third case, where there was underlying carcinomatosis, was the progress poor.

In case 1 the symptoms of spinal cord injury were present before the manipulation. In this and in the two other cases the decision to manipulate may have been ill advised, but it is not possible to conclude, simply on the basis of the observed sequelae, that there was a clear and absolute contraindication to manipulate in these cases.

Most of us would agree that the very real dangers in using non-steroidal anti-inflammatory drugs does not mean that they should never be prescribed. Neither does the occurrence of morbidity and even death after anaesthesia and surgery preclude their expert use for the relief of pain and the treatment of disease. The three cases reported need to be seen in relation to the many thousands of effective manipulative treatments given. In the region served and over 12 months a reasonable estimate would give an incidence of 3 per 1000000 treatments.

It is clearly important that manipulation should be carried out by people who are trained and skilled. It is also highly desirable that all such treatment should be in the context of good interprofessional understanding and respect, thus facilitating consultation with other specialists at any stage in the care of a patient. No one individual, be he GP, osteopath, or surgeon, can claim supreme competence and authority. We are individuals in a team.

Those of us who work in manual medicine often see patients who have for months or years been subjected to the full battery of invasive investigations, yet have not received effective treatment. In many of these cases-though not all-careful examination and the subsequent application of appropriate, precise, gentle manipulation will give almost immediate relief and set the patient on the path to full recovery.

Our rheumatologist colleagues constantly decry 